\title{
Pinworms and postmenopausal bleeding
}

\author{
H K Al-Rufaie, G H Rix, M P Pérez Clemente, T Al-Shawaf
}

\begin{abstract}
The human pinworm Enterobius vermicularis is normally found within the human gastrointestinal tract. Pregnant females migrate out of their host's anus at night to lay their eggs perianally. As a consequence of this nocturnal migration some worms find their way into adjacent orifices, most commonly the female genitourinary tract, producing irritative symptoms such as vulvovaginitis. A case of pinworm infestation of the uterus presented as postmenopausal bleeding. (F Clin Pathol 1998;51:401-402)
\end{abstract}

Keywords: Enterobius vermicularis; endometrium; postmenopausal bleeding

Department of Histopathology, West Suffolk Hospital, Bury St Edmunds, UK H K Al-Rufaie G H Rix M P Pérez Clemente

Directorate of Women's Services, Fertility Centre, St Bartholomew's Hospital, West Smithfield, London EC1, UK

T Al-Shawaf

Correspondence to: Dr H K Al-Rufaie, consultant pathologist, Department of Histopathology, West Suffolk Hospital, Hardwick Lane, Bury St Edmunds, Suffolk IP33 2QZ, UK.

Accepted for publication 30 January 1998

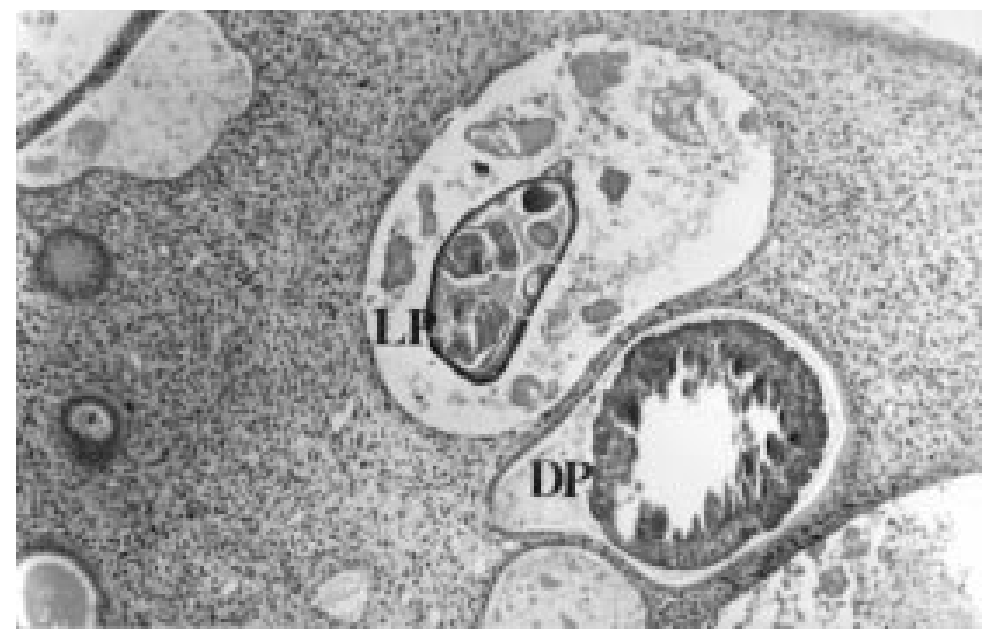

Figure 1 Dilated endometrial glands containing live (LP) and dead calcified (DP) pinworms. glandular cystic type. The endometrial stroma showed non-specific focal inflammation. Some dilated endometrial glands contained both live and degenerated calcified pinworms (fig 1).

The patient was prescribed a course of mebendazole and the general practitioner was informed in order to treat the rest of the household. Two years later the patient remains asymptomatic.

\section{Discussion}

The life cycle of the human pinworm Enterobius vermicularis takes place within the human gastrointestinal tract. Infection occurs faeco-orally and ingested ova hatch in the duodenum, developing into adult worms that colonise the large bowel, where fertilisation takes place. Pregnant females migrate out of the anus at night, lay their eggs perianally, and die. ${ }^{1}$ Nocturnal errors of navigation by gravid females can lead to their entry into adjacent orifices so that they have been found in the urinary tract as far as the kidney and in the female genital tract as far as the peritoneal cavity. ${ }^{2}$ Many carriers remain asymptomatic but the commonest symptoms are nocturnal pruritus ani.

The most usual gynaecological presentation is either the accidental finding of ova on cervical smears ${ }^{3}$ or as vulvovaginitis, especially in children. $^{24}$ Other presentations include salpingo-oophoritis, ${ }^{25}$ a pelvic or ovarian mass, ${ }^{26}$ pelvic pain, ${ }^{7}$ and in one reported case pinworms were found in a macerated embryo. ${ }^{8}$

There are only two other reported cases of vaginal bleeding associated with pinworms; Simons ${ }^{9}$ found a pinworm in the cervix of a 42 year old multipara with a six month history of blood stained vaginal discharge, while $\mathrm{Klee}^{10}$ discovered a pinworm granuloma associated with a squamous carcinoma of the cervix in a 59 year old woman with two episodes of postmenopausal bleeding. To our knowledge, ours is the first reported case of pinworms in the endometrium presenting as postmenopausal bleeding. Live and degenerated pinworms were only seen in the dilated endometrial glands in this case. No pinworms were seen in the stroma, nor were there any ova or granulomatous reactions, although pinworms and particularly their ova can produce inflammatory granulomas at various sites, including the endometrium. ${ }^{6}{ }^{11}$ The presence of the worms may have led to dilatation of glandular tissue, non-specific inflammation, and polyp formation.

1 Faust E, Russell PF, Jung RC. Clinical parasitology. Philadelphia: Lea and Febiger, 1970.

2 Symmers W St C. Pathology of oxyuriasis. Arch Pathol 1950;50:475-516.

3 Langlinais PC. Enterobius vermicularis in a vaginal smear. Acta Cytol 1969;13:40-1. 
4 Pierce AM, Hart CA. Vulvovaginitis: causes and management. Arch Dis Child 1992;67:509-12.

5 Schnell VL, Yandell R, Van Zandt S, et al. Enterobius vermicularis salpingitis: a distant episode from precipitating appendicitis. Obstet Gynecol 1992;80:553-5.

6 McMahon JN, Connolly CE, Long SV, et al. Enterobius granulomas of the uterus, ovary and pelvic peritoneum. Two case reports. Br f Obstet Gynaecol 1984;91:289-90.

7 Mayayo E, Mestres M, Sarmiento J, et al. Pelvic oxyuriasis. Acta Obstet Gynecol Scand 1986;65:805-6.
8 Mendoza E, Jorda $\mathrm{M}$, Rafel E, et al. Invasion of human embryo by Enterobius vermicularis. Arch Pathol Lab Med embryo by Entero

9 Simons EM. Entozoen in der Gebärmutter. Zentralbl Gynakol 1899;26:777-8.

10 Klee F. Beitrag zur Kenntnis des Verhaltens der Oxyuren in weiblichen Geschlechtsapparat. Zentralbl Gynakol 1920;34: 939-41.

11 Schenken JR, Tamisiea J. Enterobius vermicularis infection of the endometrium. Am J Obstet Gynecol 1956;72: 913-15. 